\title{
A Program of Cell Death and Extracellular Matrix Degradation Is Activated in the Amnion before the Onset of Labor
}

\author{
Hanqin Lei, ${ }^{\star}$ Emma E. Furth, ${ }^{\ddagger}$ Raghu Kalluri, ${ }^{\S}$ Terry Chiou, ${ }^{\star}$ Kim I. Tilly, Jonathan L. Tilly, Keith B. Elkon, ${ }^{\sharp}$ John J. Jeffrey, ${ }^{\star \star}$ \\ and Jerome F. Strauss III* \\ *Department of Obstetrics and Gynecology, ${ }^{\ddagger}$ Department of Pathology and Laboratory Medicine, and ${ }^{\S}$ Department of Medicine, \\ University of Pennsylvania, Philadelphia, Pennsylvania 19104; "Vincent Center for Reproductive Biology, Massachusetts General \\ Hospital, Boston, Massachusetts 02114; "Hospital for Special Surgery, Cornell Medical College, New York 10021; and **Department of \\ Pharmacology and Toxicology, Albany Medical College, Albany, New York 12208
}

\begin{abstract}
Fetal membranes usually rupture during the process of labor. Premature fetal membrane rupture occurs not infrequently and is associated with significant fetal and maternal morbidity. The mechanisms of normal and pathologic fetal membrane rupture are not well understood. We have examined structural and biochemical changes in the rat amnion as labor approaches in order to characterize this process in normal pregnancy. Here we report that before the onset of active labor the amnion epithelial cells undergo apoptotic cell death which encompasses degradation of $28 \mathrm{~S}$ ribosomal subunit RNA and associated $P$ proteins and fragmentation of nuclear DNA. Concurrent with these cellular changes, the amnion type I collagen matrix is degraded with the accumulation of three-quarter length type I collagen fragments in extraembryonic fluid, characteristic of the cleavage of fibrillar collagen by interstitial collagenase. Western blot and immunohistochemical analyses confirmed that interstitial collagenase protein appears in association with the loss of amnion type I collagen. We conclude that amnion epithelial cells undergo a process of programmed cell death associated with orchestrated extracellular matrix degradation which begins before the onset of active labor. Thus, fetal membrane rupture is likely to be the result of biochemical changes as well as physical forces. (J. Clin. Invest. 1996. 98:1971-1978.) Key words: amnion • apoptosis • collagen • interstitial collagenase $\bullet$ ribosomes
\end{abstract}

\section{Introduction}

The fetal membranes encapsulate the fetus and secure its intrauterine environment. During labor, the membranes usually rupture, a process that has been attributed frequently to mechanical forces (1). Recently, we characterized the histological and ultrastructural features of the rat fetal membranes, the

Address correspondence to Jerome F. Strauss III, M.D., Ph.D., 778 Clinical Research Building, 415 Curie Boulevard, Philadelphia, PA 19104. Phone: 215-898-0147; FAX: 215-573-5408; E-mail: jstrauss@ obgyn.upenn.edu

Received for publication 9 April 1996 and accepted in revised form 13 August 1996.

J. Clin. Invest.

(C) The American Society for Clinical Investigation, Inc.

0021-9738/96/11/1971/08 \$2.00

Volume 98, Number 9, November 1996, 1971-1978 amnion and visceral yolk sac placenta, at the end of pregnancy and discovered striking changes in the cells comprising the membranes as well as the extracellular matrix before the onset of active labor (2). These structural changes were particularly marked in the amnion and included delamination of amnion epithelial cells from the amnion basement membrane, ultrastructural signs of apoptosis, and a dramatic loss of fibrillar collagen from the amnion matrix. Coincident with these morphological changes, the texture of the amnion was transformed from a resilient membrane to an amorphous gel. These findings strongly suggested that fetal membranes undergo a program of terminal remodeling in preparation for parturition, challenging the notion that the fetal membranes break primarily because of physical forces (1).

The goals of this study were to determine if cells of the amnion display characteristic biochemical features of apoptosis at term, including nuclear DNA fragmentation (3) and degradation of ribosomal RNA (4), and if these changes are associated with the activation of collagenolytic enzymes that degrade the primary amnion fibrillar collagen, type I collagen $(2,5)$.

\section{Methods}

Animals. Timed pregnant Sprague-Dawley rats were purchased from Zivic-Miller Laboratories, Inc. (Allison Park, PA). These animals deliver between 1300 and $1600 \mathrm{~h}$ on day 21 of gestation. Animals were killed by $\mathrm{CO}_{2}$ asphyxiation between 0900 and $1000 \mathrm{~h}$ according to Institutional Animal Use and Care Committee guidelines, on days 18-21 of pregnancy. Extraembryonic fluid was collected from individual sacs into syringes through 21-gauge needles as described previously (6). The amnions and visceral yolk sac placentae were then isolated and generally pooled for biochemical and histological analyses. Experiments were routinely repeated on at least two separate occasions using tissues collected from different animals to establish the generality of the results.

Immunohistochemical determination of nuclear DNA fragmentation by in situ end labeling. The method of Wijsman et al. (7) was used to detect nuclear DNA fragmentation in formalin-fixed, paraffin-embedded tissue. To quantitate the extent of nuclear DNA fragmentation, sections from fetal membranes on each day of pregnancy studied were blindly analyzed for positive nuclear staining. $10 \mathrm{high}$ power fields $(\times 400)$ were randomly selected and the number of positive nuclei in each field was counted.

Electrophoretic analysis of genomic DNA internucleosomal fragmentation. DNA was isolated as described by Tilly and Hsueh (8). Amnions and yolk sac placenta were homogenized in cold homogenization buffer consisting of $0.1 \mathrm{M} \mathrm{NaCl}, 0.01 \mathrm{M}$ EDTA, $0.3 \mathrm{M}$ Tris$\mathrm{HCl}, 0.2 \mathrm{M}$ sucrose, $\mathrm{pH}$ 8.0, and then incubated with SDS $(0.65 \mathrm{mg}$ in $100 \mathrm{ml}$ buffer) at $65^{\circ} \mathrm{C}$ for $30 \mathrm{~min}$ in a shaking water bath. The samples were extracted twice with phenol/chloroform/isoamyl alcohol (24:24:1) and ethanol precipitated. RNase treatment was used to remove RNA contamination. The DNA samples obtained were analyzed for inter- 
nucleosomal cleavage using the terminal transferase DNA labeling reaction as described by Tilly (9). $250 \mathrm{ng}$ of labeled DNA from each sample was subjected to electrophoresis through a $2 \%$ agarose gel. The gel was dried and subjected to autoradiography after which DNA fractions from each lane $<10 \mathrm{~kb}$ were excised and counted with a liquid scintillation counter.

Analysis of $28 S$ ribosomal subunit RNA and ribosome-associated proteins. Total RNA was extracted from amnions and yolk sac placentae and size-fractionated on agarose gels (10). After Northern transfer, the blots were probed sequentially with a human $28 \mathrm{~S}$ rRNA cDNA and an $18 \mathrm{~S}$ rRNA oligonucleotide (6).

Proteins extracted from amnions with RIPA buffer (50 mM Tris, $1 \%$ NP-40, $0.1 \%$ deoxycholate, $0.1 \%$ SDS, $150 \mathrm{mM} \mathrm{NaCl}, 10 \mu \mathrm{g} / \mathrm{ml}$ aprotinin, $1 \mathrm{mM}$ EDTA) were subjected to Western blotting using an autoimmune serum derived from a patient with systemic lupus erythematosus that recognizes the ribosome-associated proteins Po, P1, and P3 (11) or an antibody against ezrin, kindly provided by Dr. Anthony Bretscher (Cornell University). Protein was quantitated by the method of Bradford (12).

Western blot analysis of type I collagen and interstitial collagenase expression. Fibrillar collagens were extracted from amnion according to the method of Bass et al. (13) with modifications. In brief, the rat amnions (18-30 mg of tissue) were dissolved in $0.5 \mathrm{M}$ acetic acid containing $1 \mathrm{mM}$ PMSF and $5 \mathrm{mM}$ EDTA. All samples were extracted for $2 \mathrm{~d}$ with stirring at $4^{\circ} \mathrm{C}$, followed by centrifugation at $10,000 \mathrm{rpm}$ for $10 \mathrm{~min}$. The supernatants were collected and then precipitated by 10 vol of ethanol. The pellets were dissolved in SDS-PAGE loading buffer. Equal aliquots of the extract suspended in sample buffer were subjected to SDS-PAGE and the gels were either Silver stained or used for Western blotting as described below.

Interstitial collagenase of rat amnion was extracted in RIPA buffer containing $2 \mathrm{M}$ guanidine $\mathrm{HCl}$. After centrifugation, the supernatants were collected and dialyzed overnight against water at $4^{\circ} \mathrm{C}$.

Equal aliquots of the collagen extract or equal amounts of protein or equal volumes of amniotic fluid were subjected to Western blotting using specific antibodies against rat type I collagen or interstitial collagenase $(14,15)$. The anti-rat type I collagen antibody was prepared by injection of acid-soluble rat tail type I collagen, prepared according to the method of Bornstein (16) into rabbits (500 $\mu \mathrm{g}$ initial injection and a $500 \mu \mathrm{g}$ boost $21 \mathrm{~d}$ later). The Amersham ECL system was used to detect antibody bound to antigen (6) (Amersham Corp., Arlington Heights, IL).

Immunohistochemical localization of type I collagen and interstitial collagenase. Paraffin-embedded tissue sections were used for immunostaining using the avidin-biotin-peroxidase complex technique (17). Tissues were fixed in Bouin's solution for $24 \mathrm{~h}$. The fixed tissues were embedded in paraffin, and 3-5- $\mu \mathrm{m}$ sections were prepared. Sections were deparaffinized and rehydrated. After blocking of endogenous peroxidase activity with $2 \%$ hydrogen peroxide in methanol for $20 \mathrm{~min}$, the slides were incubated with normal goat serum for $20 \mathrm{~min}$ at $37^{\circ} \mathrm{C}$. Primary antibody was incubated for $45 \mathrm{~min}$ at $37^{\circ} \mathrm{C}$ and followed by 30 - and 45 -min incubations with the biotinylated secondary antibody and avidin-biotin-peroxidase complex, respectively, at $37^{\circ} \mathrm{C}$. Reaction product was developed with diaminobenzidine tetrahydrochloride and sections were counterstained with Harris hematoxylin. Negative
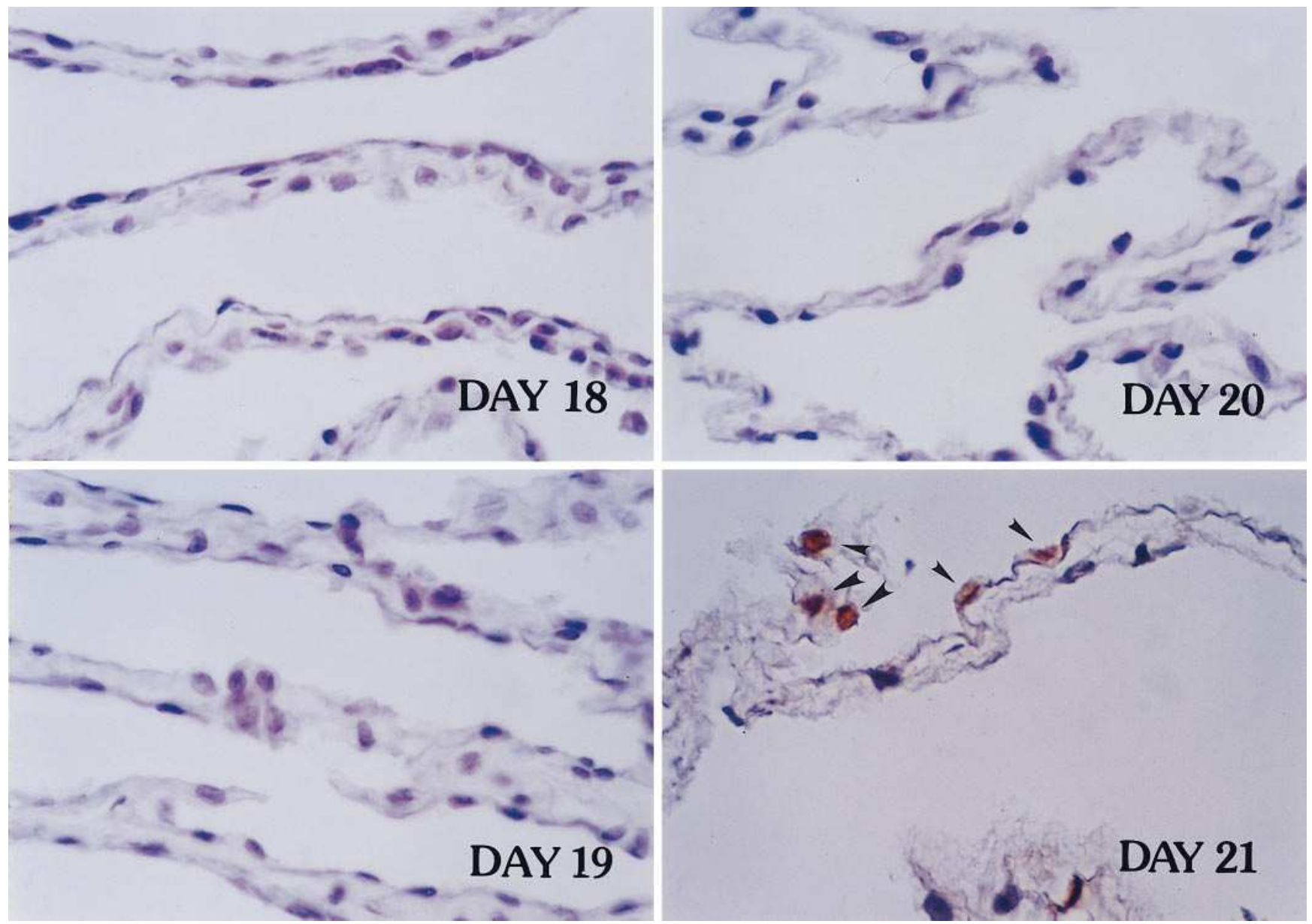

Figure 1. Demonstration of nuclear DNA fragmentation by detection of 3 '-end-labeled fragments. Sections of rat amnion were processed for ISEL as described in the text. Nuclear DNA fragmentation was not detected on days 18 and 19. An occasional nucleus was stained on day 20, but stained nuclei (arrowheads) were frequently seen in sections of amnion collected on day 21. 


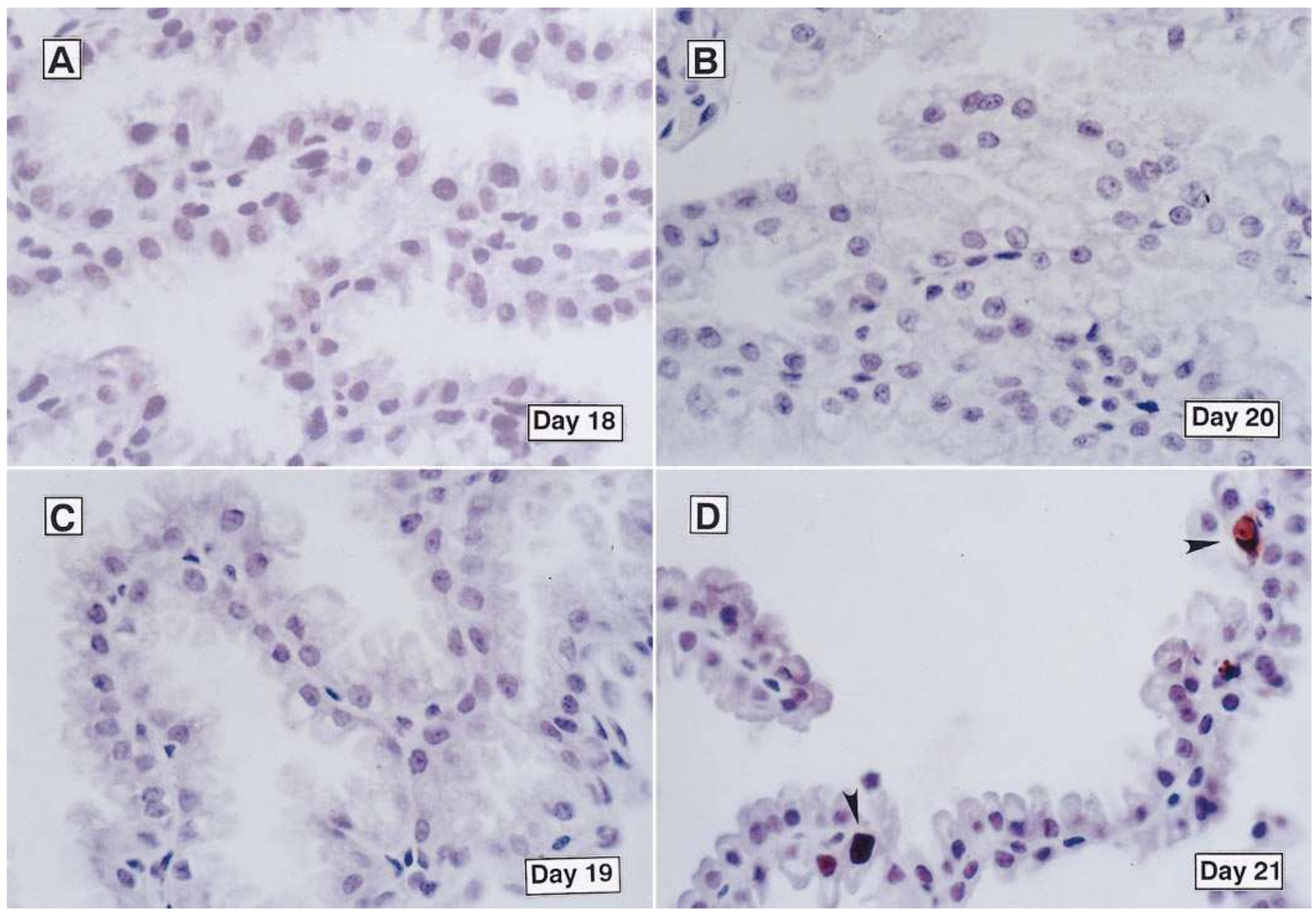

Figure 2. Nuclear DNA fragmentation in the visceral yolk sac placenta. No evidence of nuclear DNA fragmentation was observed by ISEL in the visceral yolk sac placenta on days 18-20 of pregnancy. Occasional nuclei were stained on day 21 (arrowheads).

controls consisted of exclusion of the primary antibody. To corroborate the specificity, the antibodies were neutralized with purified rat interstitial collagenase and type I collagen, respectively, overnight at $4^{\circ} \mathrm{C}$. The controls were subjected to the same treatment without antigens.

\section{Results}

Endonuclease cleavage of amnion epithelial cell genomic DNA before the onset of labor. Immunohistochemical localization of in situ $3^{\prime}$-end-labeled DNA fragments (ISEL) ${ }^{1}$ revealed that these fragments were not detectable in amnion on days 18 and 19 of pregnancy (Fig. 1). An occasional nucleus was labeled on day 20 , whereas labeled nuclei in the amnion epithelium were frequently encountered on sections of amnion collected on the morning of day 21. Quantitative analysis of the number of nuclei showing DNA fragmentation revealed none in sections from day 18 and 19 amnions, $1.4 \%$ of the nuclei stained on day 20 , and $9.2 \%$ of the nuclei stained on day 21 . Nuclear DNA fragmentation in visceral yolk sac placenta was not detected on days 18-20 and was only sporadic on day 21 (Fig. 2). Quantitative analysis of nuclear DNA fragmentation revealed no stained nuclei on days 18 and $19,0.1 \%$ stained on day 20 , and $0.2 \%$ on day 21 .

1. Abbreviations used in this paper: ISEL, in situ end labeling; MMP, matrix metalloproteinase.
DNA isolated from amnions on days 20 and 21 demonstrated the characteristic 180-200-bp internucleosomal cleavage fragments (18), which were most prominent on day 21 (Fig. 3). These were not evident on days 18 or 19 of pregnancy nor in DNA extracted from visceral yolk sac placentae. These findings are consistent with the analysis of nuclear DNA fragmentation by ISEL.

Catabolism of $28 S$ ribosomal subunit RNA and ribosomal proteins. Apoptotic cell death has been shown recently to include degradation of ribosomal subunit components. We examined the $18 \mathrm{~S}$ and $28 \mathrm{~S}$ rRNA and ribosomal $\mathrm{P}$ proteins in amnions and visceral yolk sac placentae on different days of pregnancy. On day 21, there was a pronounced degradation of 28S rRNA evident by Northern blotting using a 28S rRNA specific probe (Fig. 4). On day 20, the 28S rRNA appeared to be intact. In contrast, $18 \mathrm{~S}$ rRNA, although subject to some degradation on day 21, remained more intact than the $28 \mathrm{~S}$ rRNA. Degradation of 28S rRNA was not evident in visceral yolk sac placenta on day 21.

The gross degradation of $28 \mathrm{~S}$ rRNA occurred after a decline in ribosomal $\mathrm{P}$ proteins, which comprise a pentavalent complex $\left(\mathrm{P}_{2} \cdot \mathrm{P} 2_{2} \cdot \mathrm{Po}\right)$ situated on the stalk of the large subunit of ribosomes (19). The three different P proteins, P0 $(38 \mathrm{kD})$, P1 (19 kD), and P2 (17 kD), were all reduced by day 20 compared with day 18 samples and were markedly depleted by day 21 (Fig. 5). Despite the loss of these amnion ribosome-associ- 
Days 18

19

20

21
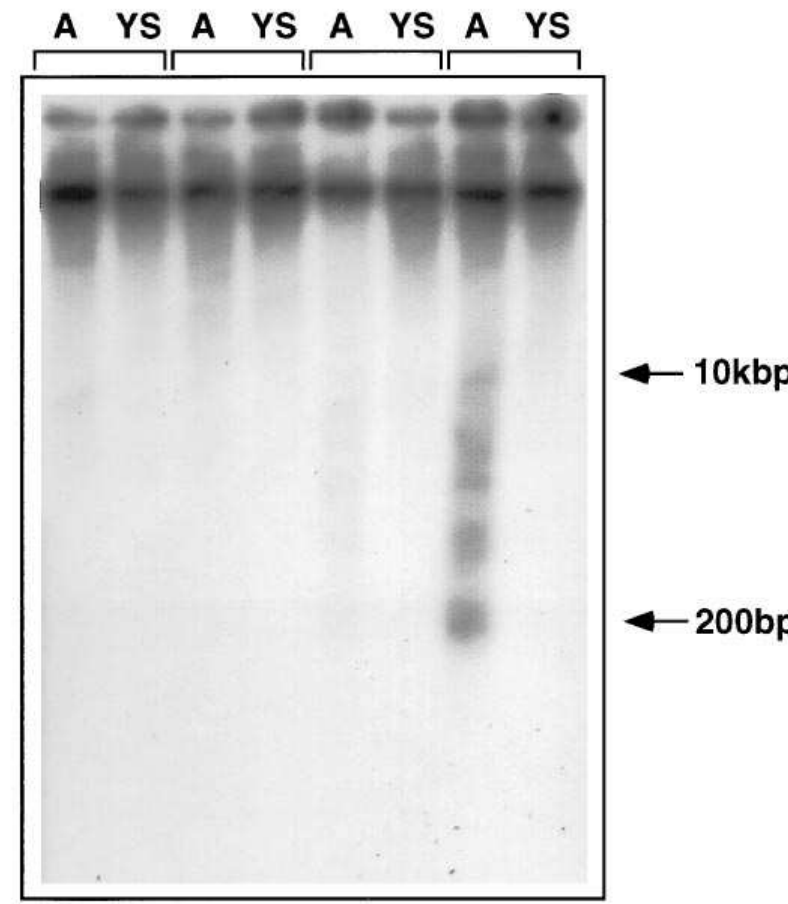

Figure 3. Genomic DNA fragmentation in the amnion by day 21. DNA was isolated from amnions $(A)$ and visceral yolk sac placenta $(Y S)$, labeled using the terminal transferase reaction and $250 \mathrm{ng} / \mathrm{lane}$ subjected to electrophoresis. Autoradiography revealed internucleosomal cleavage, reflected by a laddering of DNA fragments in amnion DNA only on days 20 and 21. Quantitation of radioactive DNA fragments of $<10 \mathrm{kbp}$ in size as counts per minute yielded the following results: day 18: $A=788 ; Y S=550$; day 19: $A=686 ; Y S=508$; day 20: $A=1322 ; Y S=578$; day $21: A=3504 ; Y S=583$.

ated proteins on days 20 and 21, Western blot analysis of the 80-kD cytoskeleton-associated protein, ezrin, and Coomassie blue staining of the amnion extracts revealed that other proteins remained intact. These observations, in conjunction with
DAYS OF PREGNANCY
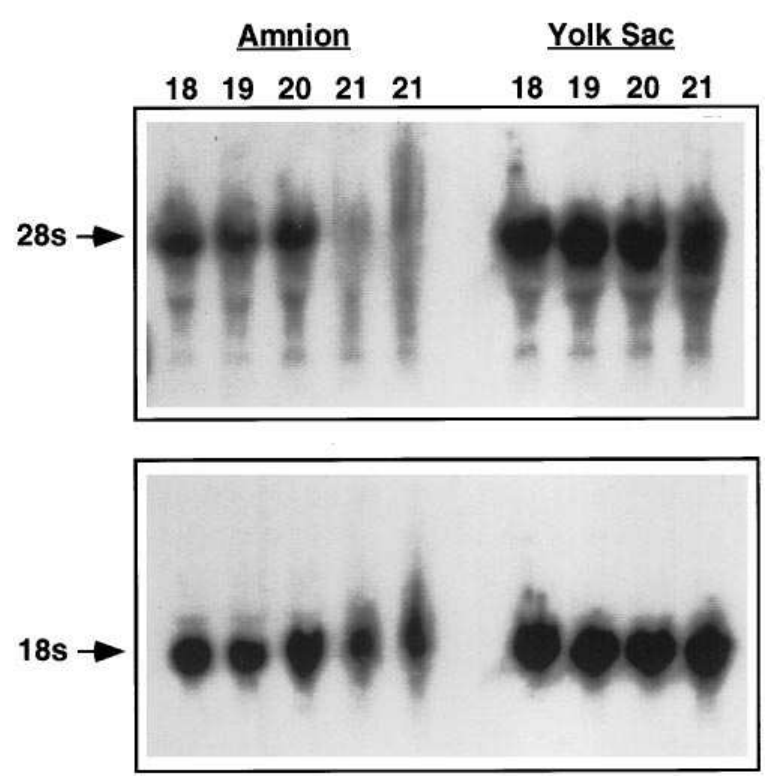

Figure 4. Degradation of $28 \mathrm{~S}$ rRNA in amnion on day 21. Total RNA was extracted from amnions and visceral yolk sac placentae on the indicated days of pregnancy and size fractionated on a $0.8 \%$ agarose gel. RNA was transferred to a nylon membrane and then probed sequentially with specific $28 \mathrm{~S}$ and $18 \mathrm{~S}$ rRNA probes. Two different RNA samples prepared from amnions collected on day 21 were analyzed.

the catabolism of the $28 \mathrm{~S}$ rRNA, suggest that breakdown of amnion ribosomes occurs before delivery.

Loss of amnion type I collagen. Our previous histological and ultrastructural studies of the rat amnion at term indicated that there was a dramatic loss of fibrillar collagen from the amnion matrix by day 21 of pregnancy. Immunohistochemical studies documented a striking reduction in type I collagen from the amnion on day 21 compared with day 18 (Fig. 6). These findings were substantiated by analysis of fibrillar col-
A
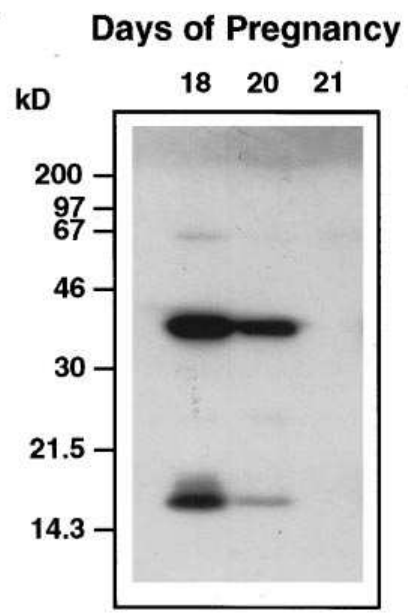

B

\section{Days of Pregnancy}

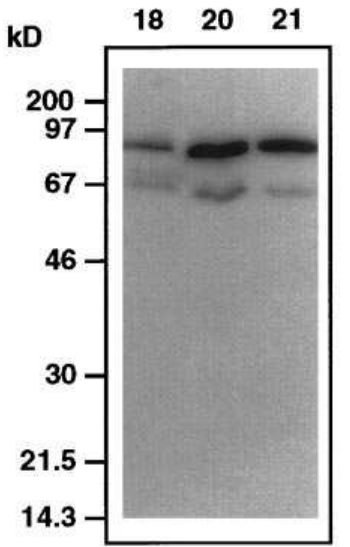

C

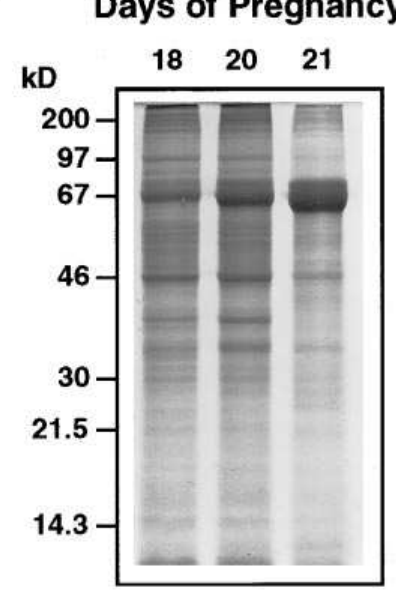

Figure 5. Loss of ribosomal $\mathrm{P}$ proteins from amnion on days 20 and 21 of pregnancy. Western blot analysis was carried out on protein extracts isolated from amnions on the indicated days of pregnancy using an autoimmune serum recognizing P proteins $(A)$ or an antibody to ezrin $(B)$. $C$ shows a Coomassie blue stained gel. Each lane was loaded with $20 \mu \mathrm{g}$ of protein. 


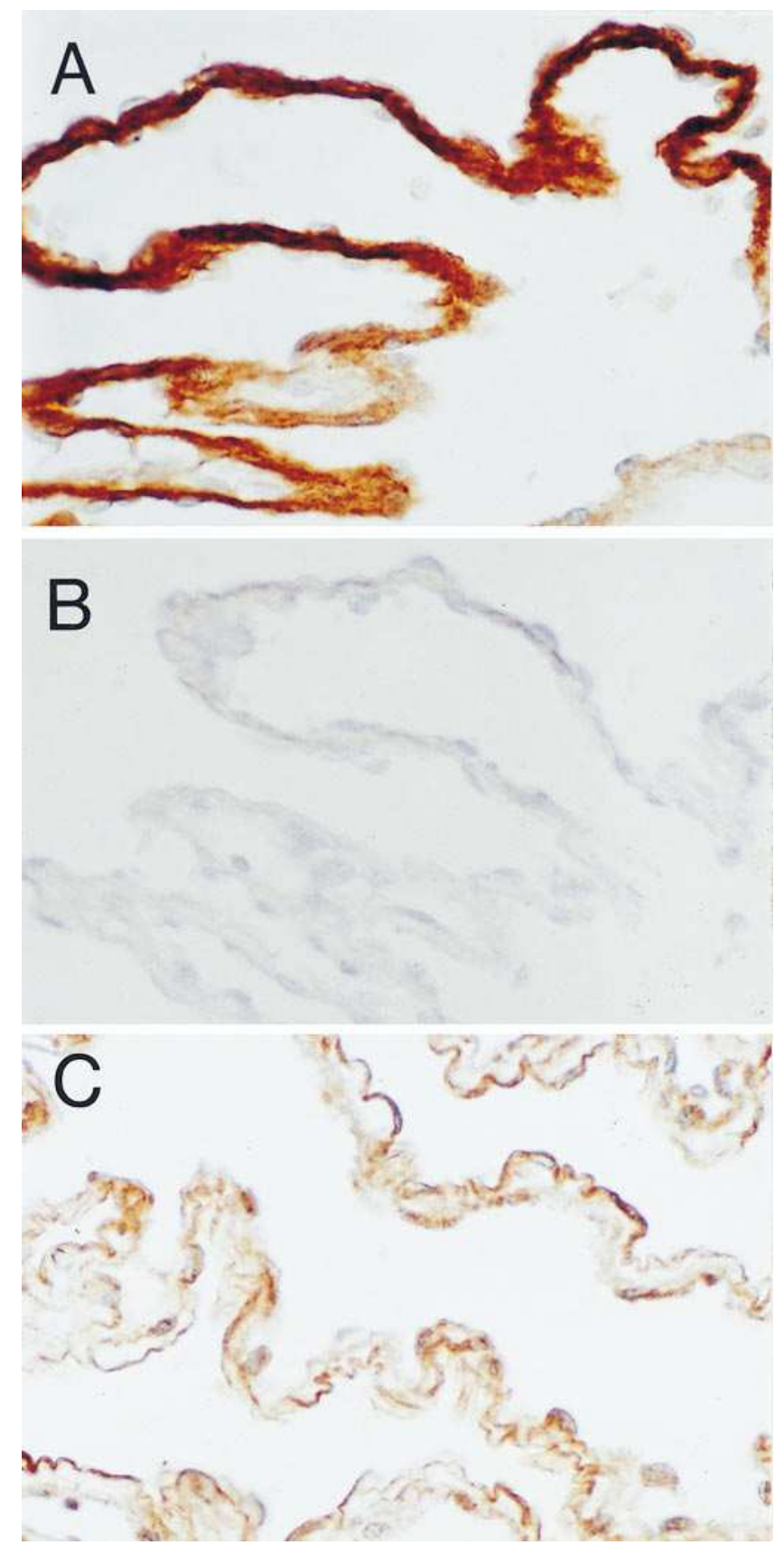

Figure 6. Loss of type I collagen from the amnion by day 21 . Sections of amnion collected on day $18(A$ and $B$ ) or day $21(C)$ were stained with an antibody to rat tail type I collagen. Intense staining in the amnion matrix is seen on day $18(A)$ and markedly reduced immunostaining was found on day $21(C)$. Adsorption of the antiserum with native type I collagen abolished immunostaining of the amnion on day $18(B)$, demonstrating specificity of the procedure.

lagen extracts of amnion by SDS-PAGE followed by Silver staining and Western blotting. These analyses demonstrated loss of $\alpha_{1}(\mathrm{I})$ and $\alpha_{2}(\mathrm{I})$ collagen monomers by day 20 and a marked reduction by day 21 (Fig. 7). Analysis of extraembryonic fluid from the same animals revealed type I collagen immunoreactivity migrating with a molecular mass of $75 \mathrm{kD}$, representing the three-quarter length tropocollagen fragment generated by the action of interstitial collagenase on fibrillar collagen (20), first on day 19, with increased levels on days 20 and 21 . The expected $30-\mathrm{kD}$ one-quarter length fragment was not detectable in these studies.

Appearance of immunoreactive interstitial collagenase in amnion and extraembryonic fluid. The loss of type I collagen immunoreactivity from amnions by day 21 as demonstrated by immunohistochemistry and Western blot analysis and the simultaneous accumulation of type I collagen fragments characteristic of the cleavage reaction of interstitial collagenase in extraembryonic fluid strongly suggested that an interstitial collagenase was induced in amnion immediately before the onset of labor. Western blot analysis of amnion extracts with a polyclonal antibody directed against rat interstitial collagenase demonstrated immunoreactive protein migrating in SDSPAGE with a molecular mass of $45 \mathrm{kD}$, characteristic of the activated enzyme (Fig. 8) (5, 21, 22). This protein was not detected on earlier days of pregnancy, but may have been present before day 21 in an unextractable form. Extraembryonic fluid contained an immunoreactive $55-\mathrm{kD}$ protein, reflecting the interstitial collagenase proenzyme, on days 20 and 21, but not on days 18 and 19. This suggests secretion of some proenzyme from the fetal membranes. Immunohistochemistry using the same antibody indicated the presence of interstitial collagenase in amnion cells on days 20 and 21, but not on day 18 (Fig. 9).

\section{Discussion}

The present observations provide strong evidence for a program of cell demise and extracellular matrix catabolism in the rat amnion before the onset of active labor. This program includes catabolism of $28 \mathrm{~S}$ ribosomal subunit components, the endonuclease cleavage of genomic DNA, and the accumulation of a matrix metalloproteinase (MMP). The net results of these changes are death of the amnion epithelial cells and digestion of the underlying collagenous matrix. These events turn the amnion from a resilient translucent sheet into a formless gel.

An immunohistochemical assay based on the detection of 3'-end-labeled DNA fragments (ISEL) revealed significant nuclear DNA degradation in the amnion epithelium on day 21, a process which was initiated on day 20 . The visceral yolk sac placenta was affected to a far lesser extent, suggesting that distinct mechanisms underlie the structural changes in the two fetal membranes at term. The results of the ISEL analysis were corroborated by the demonstration of internucleosomal DNA fragments of 180-200 bp in DNA extracted from amnion on days 20 and 21 (18). These fragments were not detected in amnion on days 18 or 19 or in the visceral yolk sac placentae, even on day 21. Collectively, these observations demonstrate the characteristic endonuclease digestion of nuclear DNA associated with apoptotic cell demise.

The catabolism of ribosomal subunit components in the amnion before labor is of interest in light of recent observations of specific cleavage of $28 \mathrm{~S}$ ribosomal RNA during apoptosis in other systems (4). Before the gross degradation of $28 \mathrm{~S}$ rRNA, ribosomal $\mathrm{P}$ proteins were depleted. These proteins are thought to be required for all phases of protein synthesis: initiation, translation, and termination (23). The almost complete degradation of 28S rRNA observed on day 21 is clearly a far advanced stage of rRNA catabolism which may be the end result of the initial specific cleavage flanking the hypervariable domains described by Houge and colleagues $(4,24)$. The $70-\mathrm{kD}$ 
A

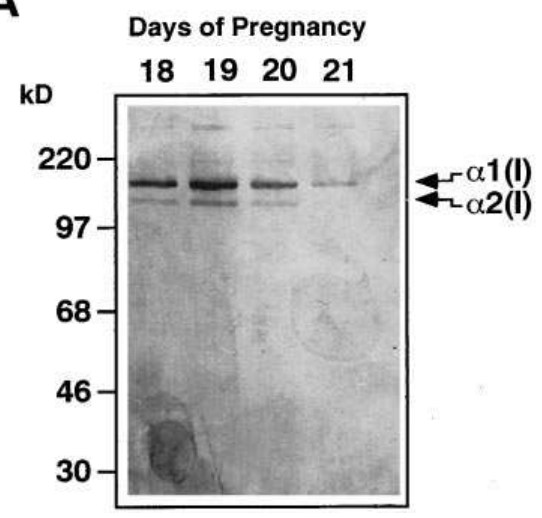

B

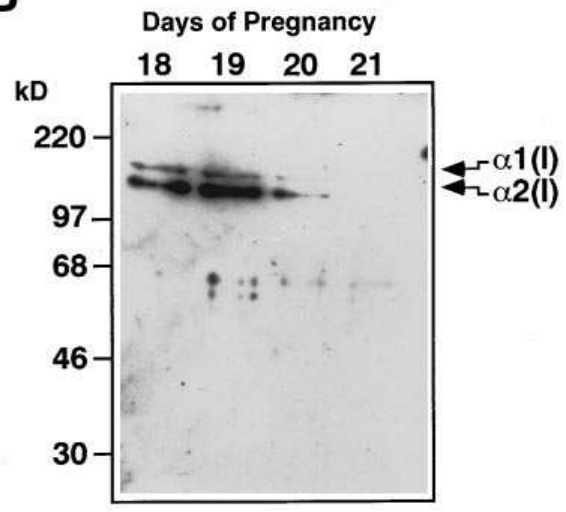

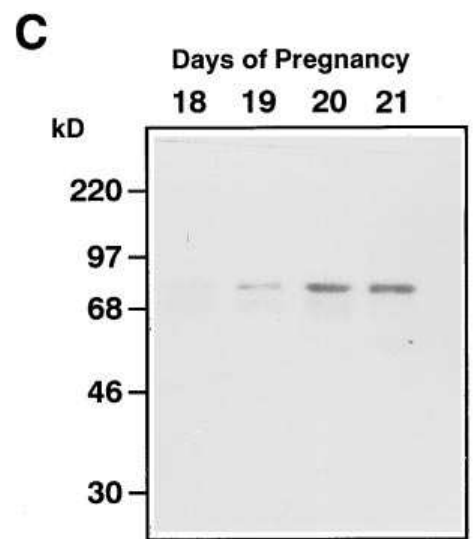

Figure 7. Analysis of type I collagen extracted from amnions and present in extraembryonic fluid. Collagens were extracted from amnions (18 $\mathrm{mg}$ ) collected on the indicated days of gestation and then subjected to SDS-PAGE followed by Silver staining $(A)$ or Western blotting with an anti-rat type I collagen antibody $(B)$. Extraembryonic fluids $(3 \mu \mathrm{l} /$ lane $)$ collected on the same days were also analyzed by Western blotting $(C)$. Type I collagen $\alpha_{1}(\mathrm{I})$ and $\alpha_{2}(\mathrm{I})$ were progressively lost from the amnion and three-quarter length type I collagen fragments, $\mathrm{TC}^{\mathrm{A}}$, accumulated in extraembryonic fluid reflecting degradation of the amnion matrix.

protein component of the U1 small nuclear ribonucleoprotein is also characteristically degraded during apoptotic cell death (25). Thus, it is evident that apoptosis encompasses significant changes in RNA and associated proteins as well as genomic DNA. Although degradation of $28 \mathrm{~S}$ ribosomal RNA occurs, many mRNAs accumulate as the amnion cells undergo apoptosis. Preliminary analysis of amnion mRNAs by differential display demonstrated a number of transcripts that increased on day 21 of pregnancy while others declined (26).

Collagens are broken down by a family of MMPs (21, 22, 27). Collagenases are the primary members of this family that degrade fibrillar collagens, collagens types I, II, and III. Type I collagen is the major structural component of the amnion (5). The cleavage of native type I collagen by interstitial collagenase occurs at a very specific site, the peptide bonds between Gly $_{775}$ and $\mathrm{Ile}_{776}$ of the $\alpha_{1}(\mathrm{I})$ chain and Gly $\mathrm{y}_{775}$ and $\mathrm{Leu}_{776}$ of the $\alpha_{2}(\mathrm{I})$ chain (18). This cleavage releases two fragments: threequarters $\left(\mathrm{TC}^{\mathrm{A}}\right)$ and one-quarter $\left(\mathrm{TC}^{\mathrm{B}}\right)$ of the total length of the type I collagen triple helix. Our SDS-PAGE analysis of amnions and extraembryonic fluid indicated that type I col- lagen fibrils were depleted from the amnions and that threequarter length fragments accumulated in the extraembryonic fluid. These findings, in conjunction with the above-noted appearance of immunoreactive interstitial collagenase, strongly suggest that the degradation of type I collagen is the result of the increase in interstitial collagenase activity, although roles for other enzymes cannot be excluded at this time. The source of this enzyme appears to be the amnion epithelial and fibroblast cells, based upon the localization of immunoreactive interstitial collagenase.

Our earlier studies demonstrated an increase in the type IV collagenase, MMP-9, in rat (6) and human (28) amnion at term. In the rat amnion, MMP-9 mRNA, protein, and activity were induced by day 21 . This enzyme may participate in the degradation of basement membrane collagens and cause the detachment of the epithelial cells from the collagenous matrix. Thus, other matrix degrading enzymes in addition to interstitial collagenase are induced as part of the terminal changes in the amnion.

This study provides a compelling argument for terminal re-
A

\section{Days of Pregnancy}

18192021

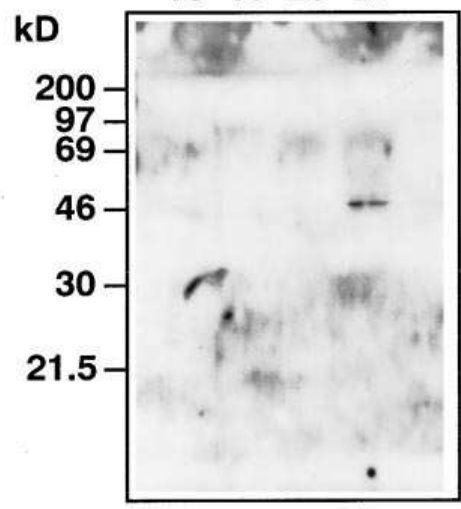

B

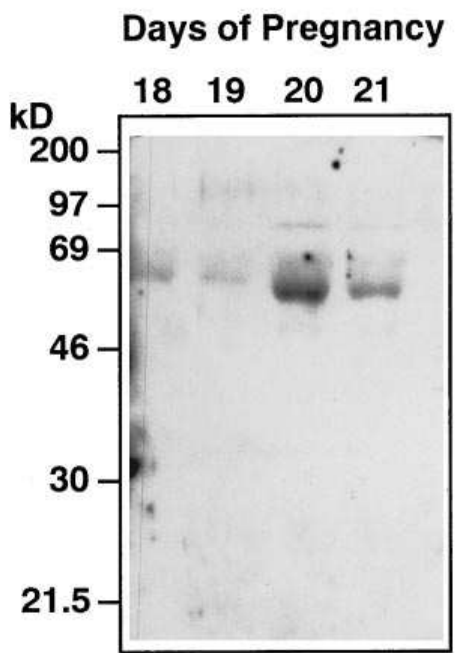

Figure 8. Immunoreactive interstitial collagenase appears in the amnion on day 21. $(A)$ Extracts of amnion prepared on the indicated days were subjected to Western blotting with a specific anti-rat interstitial collagenase antibody. An immunoreactive $45-\mathrm{kD}$ protein, representing the activated form of interstitial collagenase, was detected only on day 21. (B) Extraembryonic fluid $(10 \mu \mathrm{l})$ was also subjected to Western blotting using the anti-interstitial collagenase antibody. An immunoreactive 55-kD band is detected on days 20 and 21, representing the proenzyme. 

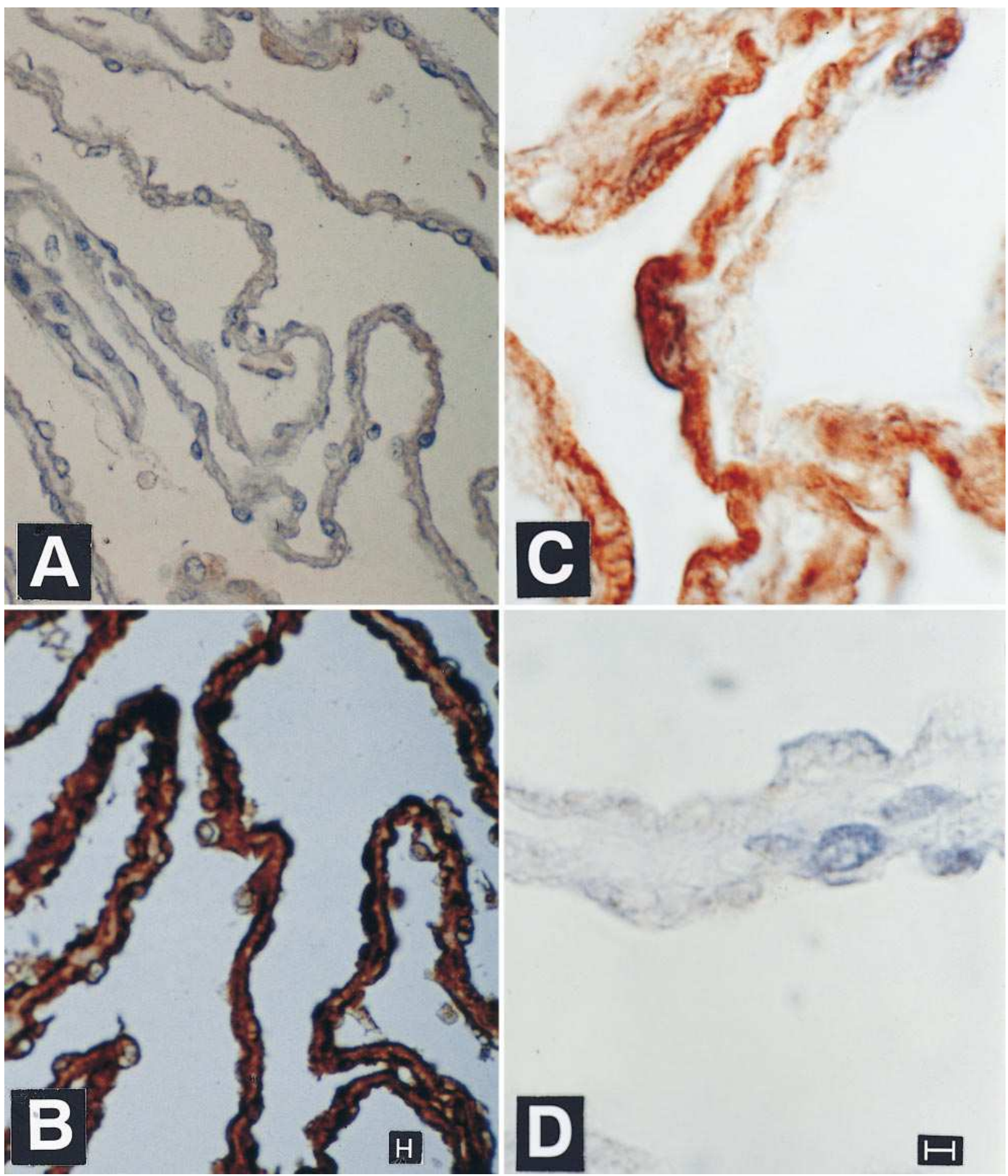

Figure 9. Localization of interstitial collagenase in the amnion. Immunohistochemical localization of interstitial collagenase to amnion epithelium and fibroblast cells on days $18(A), 20(B)$, and $21(C)$. Neutralization of the antiserum with purified antigen abolished immunostaining on a section of day 21 amnion $(D)$. Bar, $10 \mu \mathrm{m}$.

modeling of the fetal membranes as a prelude to normal parturition. This notion contrasts with the widely held idea that fetal membrane structure is altered as a consequence of physical forces (1) rather than molecular and biochemical phenomena. These concepts are not necessarily at odds, since physical forces could activate a cascade of biochemical changes through alterations in gene expression, and thus not simply break the membranes.

This study has catalogued some of the major events that take place in the amnion, particularly the amnion epithelium and fibrillar collagen matrix, as labor approaches. The exact temporal relationships of these alterations and their functional 
relationships, if any, remain to be determined. It would appear that some of these changes begin on or before day 20 , becoming progressively more marked on day 21 . Others seem to represent more terminal events. Thus, $28 \mathrm{~S}$ ribosomal subunit $\mathrm{P}$ proteins are significantly reduced by day 20 , but $28 \mathrm{~S}$ rRNA is not yet grossly degraded. Evidence for increased interstitial collagenase action is apparent by day 20 , but most marked on day 21. Genomic DNA fragmentation was also detected on day 20 , but was most striking on day 21 . These observations indicate that selective changes in gene expression are initiated by day 20, progressing to extensive degradation of ribosomal RNA and genomic DNA in later stages.

Our analyses could not disclose the precise sequence of changes in the amnion cells as labor approaches, particularly the relationships among onset of ribosome large subunit catabolism, the appearance of interstitial collagenase, and fragmentation of nuclear DNA. However, we can speculate on the sequences of changes based on our data. Our immunohistochemical studies suggested the presence of interstitial collagenase in amnion cells by day 20, but more sporadic nuclear DNA fragmentation at this time. Thus, it is probable that the appearance of interstitial collagenase precedes endonuclease activation. Since the collagenase mRNA must be translated, its upregulation and its translation most probably occur before the large ribosome subunits are degraded. Therefore, induction of MMPs may be one of the earliest events in the coordinated dismantling of the amnion.

The factors that trigger these striking changes in the amnion before the onset of labor have not yet been elucidated. They may include changes in steroid hormones or various cytokines. The rodent model we have used promises to be a useful system for the understanding of this process. Since similar changes in the amnion occur in the mouse, the roles of specific genes in the remodeling of the amnion can now be examined using transgenic animals and gene knockouts (29).

The premature rupture of fetal membranes represents a significant clinical problem that frequently leads to premature delivery and fetal and maternal morbidity (30). Structural changes in the human amnion not unlike those we have described in the rat are localized to the site of normal membrane rupture (31). However, it is not yet known whether the changes in the amnion reported here are reflective of changes that occur in pathological conditions.

\section{Acknowledgments}

This study was supported by National Institutes of Health grants HD34612 (J.F. Strauss III), HD-34226 and AG-12279 (J.L. Tilly), HD05291 (J.J. Jeffrey); and grants from the March of Dimes Birth Defects Foundation (J.F. Strauss III) and Rockefeller Foundation (H. Lei).

\section{References}

1. Schmidt, W. 1992. The amniotic fluid compartment: the fetal habitat. Anat. Embryol. Cell Biol. 124:1-100.

2. Paavola, L.G., E.E. Furth, V. Delgado, C.O. Boyd, C.C. Jacobs, H. Lei, and J.F. Strauss III. 1995. Striking changes in the structure and organization of rat fetal membranes precede parturition. Biol. Reprod. 53:321-338.

3. Wyllie, A.H., J.F.R. Kerr, and A.R. Currie. 1980. Cell death: the significance of apoptosis. Int. Rev. Cytol. 68:251-306.

4. Houge, G., B. Robaye, T.S. Eikhom, J. Golstein, G. Mellgren, B.T. Gjertsen, M. Lanotte, and S.O. Doskeland. 1995. Fine mapping of 28S rRNA sites specifically cleaved in cells undergoing apoptosis. Mol. Cell. Biol. 15:2051-2062.

5. Malak, T.M., C.D. Ockleford, S.C. Bell, R. Dalgleish, N. Bright, and J.
Macvicar. 1993. Confocal immunofluorescence localization of collagen type I, III, IV, V and their ultrastructural organization in term human fetal membranes. Placenta. 14:385-406.

6. Lei, H., F. Vadillo-Ortega, L.G. Paavola, and J.F. Strauss III. 1995. $92-$ KDa gelatinase (matrix metalloproteinase-9) is induced in rat amnion immediately prior to parturition. Biol. Reprod. 53:339-344.

7. Wijsman, J.H., R.R. Jonker, R. Keijzer, C.J. van de Velde, C.J. Cornelisse, and J.H. van Dierendonck. 1993. A new method to detect apoptosis in paraffin section: in situ end-labeling of fragmented DNA. J. Histochem. Cytochem. 41:7-12.

8. Tilly, J.L., and A.J.W. Hsueh. 1993. Microscale autoradiographic method for the qualitative and quantitative analysis of apoptotic DNA fragmentation. $J$. Cell. Physiol. 154:519-526.

9. Tilly, J.L. 1994. Use of the terminal transferase DNA labeling reaction for biochemical and in situ analysis of apoptosis. In Cell Biology: A Laboratory Handbook. J.E. Celis, editor. Academic Press, San Diego. 330-337.

10. Sambrook, J., E.F. Fritsch, and T. Maniatis. 1989. Molecular Cloning: A Laboratory Manual. Cold Spring Harbor Laboratory Press, Plainview, NY.

11. Elkon, K.B., A.P. Parnassa, and C.L. Foster. 1985. Lupus autoantibodies target the ribosomal P proteins. J. Exp. Med. 162:459-471.

12. Bradford, M.M. 1976. A rapid and sensitive method for the quantitation of microgram quantities of protein utilizing the principle of protein dye-binding. Anal. Biochem. 72:248-254.

13. Bass, L.S., N. Moazami, J. Pocsidio, M.C. Oz, P. LoGerfo, and M.R. Treat. 1992. Changes in type I collagen following laser welding. Lasers Surg. Med. 12:500-505.

14. Jeffrey, J.J., W.T. Roswit, and L.S. Ehlich. 1980. Regulation of collagenase production by steroids in uterine smooth muscle cells: an enzymatic and immunologic study. J. Cell. Physiol. 143:396-403.

15. Quinn, C.O., D.K. Scott, C.E. Brinckerhoff, L.M. Matrisian, J.J. Jeffrey, and N.C. Partridge. 1990. Rat collagenase: cloning, amino acid sequence comparison, and parathyroid hormone regulation in osteoblastic cells. J. Biol. Chem. 265:22342-22347.

16. Bornstein, M.B. 1958. Reconstituted rat-tail collagen used as a substrate for tissue culture on coverslips in Maximow slides and roller tubes. Lab. Invest. 7:134-137.

17. MacCalman, C.D., E.E. Furth, O. Omigbodun, M. Bronner, C. Coutifaris, and J.F. Strauss III. 1996. Regulated expression of cadherin-11 in human epithelial cells: a role for cadherin-11 in trophoblast endometrium interactions? Dev. Dyn. 206:201-211.

18. Wyllie, A.H. 1980. Glucocorticoid-induced thymocyte apoptosis is associated with endogenous endonuclease activation. Nature (Lond.). 284:555-556.

19. Uchiumi, T., T. Wahba, and R.R. Traut. 1987. Topography and stoichiometry of acidic proteins in large ribosomal subunits from Artemia salina as determined by crosslinking. Proc. Natl. Acad. Sci. USA. 84:5580-5584.

20. Birkedal-Hansen, H., W.G.I. Moore, M.K. Bodden, L.J. Windsor, B. Birkedal-Hansen, A. DeCarlo, and J.A. Engler. 1993. Matrix metalloproteinase: a review. Crit. Rev. Oral Biol. Med. 42:197-250.

21. Woessner, J.F., Jr. 1991. Matrix metalloproteinases and their inhibitors in connective tissue remodeling. FASEB (Fed. Am. Soc. Exp. Biol.) J. 5:21452154 .

22. Woessner, J.F., Jr. 1994. The family of matrix metalloproteinases. Ann. NY Acad. Sci. 732:11-21.

23. Uchiumi, T., R.R. Traut, K.B. Elkon, and R. Kominami. 1991. A human autoantibody specific for a unique conserved region of 28S ribosomal RNA inhibits the interaction of elongation factors $1 \alpha$ and 2 with ribosomes. J. Biol. Chem. 266:2054-2062.

24. Houge, G., S.O. Doskeland, R. Boe, and M. Lanotte. 1993. Selective cleavage of $28 \mathrm{~S}$ rRNA variable regions V3 and V13 in myeloid leukemia cell apoptosis. FEBS Lett. 315:16-20.

25. Casciola-Rosen, L.A., D.K. Miller, G.J. Anhalt, and A. Rosen. 1994. Specific cleavage of the 70-kDa protein component of the U1 small nuclear ribonucleoprotein is a characteristic biochemical feature of apoptotic cell death. J. Biol. Chem. 269:30757-30760.

26. Lei, H., and J.F. Strauss III. 1995. Differential display of mRNA reveals striking changes in gene expression in the rat amnion at term. Biol. Reprod. 52(Suppl. 1):185a. (Abstr. 514)

27. Matrisian, L.M. 1992. The matrix-degrading metalloproteinases. BioEssays. $14: 455-462$.

28. Vadillo-Ortega, F., G. Gonzalez-Avila, E.E. Furth, H. Lei, R.J. Muschel, W.G. Stetler-Stevenson, and J.F. Strauss III. 1995. 92-Kd type IV collagenase (matrix metalloproteinase-9) activity in human amniochorion increases with labor. Am. J. Pathol. 146:148-156.

29. Liu, X., H. Wu, M. Byrne, J. Jeffrey, S. Krane, and R. Jaenisch. 1995. A targeted mutation at the known collagenase cleavage site in mouse type I collagen impairs tissue remodeling. J. Cell Biol. 130:227-237.

30. Keirse, M.J.N.C., A. Ohlsson, P.E. Treffers, and H.H.H. Kanhai. 1989. Prelabour rupture of the membranes preterm. In Effective Care in Pregnancy and Childbirth. I. Chalmers, M. Ekin, and M.J.N.C. Keirse, editors. Oxford University Press, Oxford. 666-693.

31. Malak, T.M., and S.C. Bell. 1994. Structural characteristics of term human fetal membranes: a novel zone of extreme morphological alteration within the rupture site. Br. J. Obstet. Gynecol. 101:375-386. 